\title{
Nuevas tendencias de la museología
}

\section{François Mairesse}

\section{OpenEdition}

\section{Journals}

\section{Edición electrónica}

URL: http://journals.openedition.org/iss/543

DOI: $10.4000 /$ iss. 543

ISSN: 2306-4161

\section{Editor}

ICOM - International Council of Museums

\section{Edición impresa}

Fecha de publicación: 1 junio 2015

Paginación: 17-20

ISSN: 2309-1290

\section{Referencia electrónica}

François Mairesse, " Nuevas tendencias de la museología », ICOFOM Study Series [En línea], 43a | 2015,

Publicado el 06 febrero 2018, consultado el 24 septiembre 2020. URL : http://journals.openedition.org/ iss/543 ; DOl : https://doi.org/10.4000/iss.543 


\title{
Nuevas tendencias de la museología
}

\author{
François Mairesse \\ Presidente de ICOFOM - Universidad Sorbonne Nouvelle Paris 3, CERLIS, \\ ICCA, Francia
}

El tema elegido para el $37^{\circ}$ Simposio Internacional de ICOFOM, que tuvo lugar en París del 5 al 9 de junio de 2014, estuvo orientado a abrir nuevos escenarios de reflexión sobre el futuro de la museología. Evocar las nuevas tendencias de la museología, es reconocer que el mundo de los museos, durante estos últimos decenios, ha conocido cambios considerables, comenzando por el crecimiento de la cantidad de museos en el mundo, como así también por su transformación radical: ya sea en materia de comunicación (en relación a la exposición o al desarrollo del museo como medio de comunicación); ya sea en materia de transformación del patrimonio, en relación a lo contemporáneo o al acercamiento a los públicos. El contexto económico (el desarrollo de la lógica neoliberal en el mundo, pero también la crisis económica), así como las transformaciones tecnológicas (el desarrollo de Internet y de lo digital) han reformado radicalmente la manera de pensar el campo museal. Nos atrevemos a suponer que estas transformaciones van a continuar y llevarán a cambios en la manera de percibir el campo museal en el siglo XXI. Es dentro de tal contexto que el tema de referencia, lanzado a fines del año 2013 , fue considerado de manera resueltamente abierta, a fin de recibir contribuciones suficientemente diversas para intentar pensar, de manera global, el bosquejo de un panorama sobre los temas emergentes dentro del campo de la museología. Nueve temáticas fueron propuestas, a fin de sugerir un cierto número de escenarios de reflexión a los autores: 1. la geopolítica de la museología o las maneras de pensar el campo museal a través del mundo, 2. la epistemología de la museología en tanto que disciplina y materia de enseñanza, 3. la relación del patrimonio y la problemática de las colecciones, 4 . la educación y la comunicación, 5. la relación con lo contemporáneo, 6. los contornos de la cibermuseología, 7. la museología participativa, 8. la ética del campo museal en el siglo XXI, y finalmente 9. la historia y la proyección futura en materia de museología.

La cantidad de propuestas recibidas (más de 200 resúmenes) requirió una primera selección; más de 75 comunicaciones fueron presentadas en el coloquio de París. Una doble selección posterior permitió reunir los documentos publicados en los volúmenes 43a y b de las Series de Estudio del ICOFOM (ISS).

La diversidad de los temas evocados dentro de los diferentes artículos ha vuelto bastante difícil la distribución de las temáticas en los dos volúmenes. Ciertos escenarios sugeridos despertaron más interés que otros, imponiendo una reorganización de las temáticas. Sin embargo, algunas tendencias sobresalen de este conjunto, lo que nos ha permitido proponer la presente distribución en dos volúmenes, tanto para los artículos teóricos como para los estudios de caso (segunda parte de cada volumen). Aunque, por razones de legibilidad, hemos preferido conservar el orden alfabético al interior de los volúmenes y de las partes.

Desde su creación el ICOFOM trabaja esencialmente sobre los 
aspectos teóricos del campo museal, a partir de una aproximación global integrando el conjunto de los museos y de las instituciones que le son próximas, así como el conjunto de las funciones museales (conservación, investigación, comunicación). Esta aproximación, es seguida por muchos miembros de ICOFOM pero, lejos de ello, no por todos los investigadores. Numerosas contribuciones presentadas a lo largo del coloquio y retomadas aquí insisten especialmente sobre ciertos aspectos específicos del museo: la institución como medio de comunicación, las exposiciones, la conservación, los informes de visitantes, etc. Esta selección nos ha permitido reagrupar, en el primer volumen (vol. 43a) los artículos referidos esencialmente a un enfoque general de la institución, o de la museología y de su evolución, mientras que hemos tratado de agrupar dentro del segundo volumen (vol. 43b) los documentos más directamente dedicados a uno de los enfoques del fenómeno museal: aquel que trata del visitante, de las funciones museales o de los aspectos éticos al que están ligados. Nos hemos dado cuenta del carácter a veces ficticio de tales agrupamientos, así como otras veces ha sido difícil distinguir los artículos teóricos y los estudios de caso de tono más específico o más práctico: la frontera entre la teoría y la práctica, lo sabemos, está lejos de ser explícita y estable. La una se nutre continuamente de la otra.

El primer volumen (vol. 43a) retoma un cierto número de cuestionamientos generales sobre el devenir del campo museal y de la museología. Varios artículos analizan los fundamentos o la historia de la disciplina a fin de comprender mejor su posible evolución. Con el objetivo de explorar la museología del siglo XXI, Deloche vuelve sobre los fundamentos; Guzin se interroga igualmente sobre uno de los temas más caros para el ICOFOM: "la museología del Este"; mientras que Brulon Soares evoca la Nueva Museología; Menezes de Carvalho y Scheiner examinan la museología a partir de la noción de campo según Bourdieu; de manera más práctica, Gachet rastrea la historia de la Lettre de OCIM. En cuanto al plan de formación, Bergeron y Carter se cuestionan sobre la evolución de la museología y sus repercusiones sobre la manera de enseñarla. Julião analiza el concepto de historicidad y sus vínculos con el museo; y Nomiku se cuestiona sobre la integridad de la museología. Sabemos que la museología se concibe y se enseña de diferentes maneras en diferentes partes del mundo. Costa, desde esta perspectiva, evoca el concepto de la "museología del sur"; mientras que Melo, Menezes de Carvalho y de Moraes analizan la idea de una "museología amazónica". Brulon Soares, Menezes de Carvalho y de Vasconcelos se preguntan finalmente, de manera más práctica, sobre las diferentes corrientes de la museología del Brasil; mientras que Sustar analiza los museos pedagógicos.

Dos elementos particulares han tenido una influencia especial sobre la manera de pensar el futuro de la museología: el desarrollo de la tecnología digital, por un lado, y los mecanismos económicos, por el otro. Conocemos la influencia de Internet y de las tecnologías de la información y de la comunicación sobre el museo y la manera de pensar su evolución. La cibermuseología constituye una de las posibilidades de considerar los nuevos contornos del campo museal, aquellos que evocan Langlois $\mathrm{y}$, de manera más práctica, Leshchenko. La evolución en la manera de concebir los mecanismos económicos constituye también un dato de vital importancia para comprender especialmente las relaciones entre el museo y el mercado del arte, aquel que Doyen explica a través del patrimonio 
etnográfico; pero es sobre todo, la crisis económica y paralelamente el desarrollo de lógicas colaborativas y participativas lo que más ha influenciado el pensamiento museal contemporáneo: las contribuciones de Agostino, de Moolhuisen y de Radice, entre otras, testimonian la importancia actual de este modo de funcionamiento particular de la institución.

El segundo volumen (vol. 43b) se refiere más directamente a la museología a partir de las funciones museales o del punto de vista de su recepción, especialmente desde el ángulo de los estudios de público. La cuestión sobre el funcionamiento del campo museal y particularmente aquel del museo, nos conduce a la reflexión ética, presente en las propuestas de Maranda y de Avila Mélendez. La ética supone el examen de los fines, y especialmente la reflexión sobre los públicos y los usuarios (potenciales, actuales y futuros) del museo. No sorprende que la pregunta acerca de los visitantes y de los públicos constituya todavía una de las puertas de entrada obligadas en el área de los investigadores del campo museal, especialmente a través del estudio de públicos, como lo podemos comprobar en los documentos de Harris, de Mijalovic y Romanello, de Schmitt, de Romanallo, de Crenn y Roustan, o aún la de Jutant y Lesaffre. La relación entre el museo y su público supone, de alguna manera, el principio del museo como sistema de comunicación, sobre el que vuelven, de manera práctica, Chuvilova y Shelengina por un lado, y Roda por el otro. Este vínculo particular entre la institución museal y su público descansa sobre una de las funciones clásicas del museo, resumida a través del principio general de comunicación, pero también generalmente evocada a través de las nociones de educación o, más recientemente, de la mediación y la inclusión. Esta perspectiva ha sido elegida por numerosos autores, tales como Cornélis y Jaminon, Dufresne-Tassé y O'Neil, enfatizando sobre las mejores prácticas en materia de educación y de mediación, pero también por Sant'Anna de Godoy (describiendo grupos de jóvenes y adultos, y los programas de alfabetización), García Ceballos (por los grupos de adultos mayores), Fontal y Marin (por los programas de inclusión) o Thévenot et al. (por los nativos digitales), todos dan testimonio de las características específicas de la institución en relación a los grupos a los que van dirigidas.

Después de la educación o la mediación, el análisis de las exposiciones constituye también una mirada clásica a partir de la cual el campo museal es investigado. Se trata de técnicas o de experiencias particulares vinculadas a la creación de exposiciones, como los estudian Schärer, Noël-Cadet y Bonniol o De Caro y, de manera más práctica, Chang y Shibata, o cuestionar la creación de la exposición diferenciándola de la exposición en sí misma, como propone Camart. La cuestión de la preservación (y más específicamente de la conservación), tema no menos importante, fue también objeto de análisis específicos: la figura del conservador es abordado por Hoffman, Jones y Burns, mientas que Smeds y Angilis ponen en cuestión por un lado el tema de la preservación como problemática de las colecciones y su continuidad ${ }^{1}$; y por otro la conservación del patrimonio inmaterial, a través de la historia oral. Finalmente el tema de la cesión de colecciones ${ }^{2}$ es evocado por Robbins a través de un estudio de museos finlandeses.

Como se puede constatar, un gran número de temas presentados

\footnotetext{
${ }^{1}$ En francés: déchets.

${ }^{2}$ En francés: aliénation.
} 
parece inscribirse como resultado de las reflexiones iniciadas desde hace varios años. ¿Es posible, en esta instancia, hablar de nuevas tendencias que emergen de estos documentos? Es evidente que estas últimas emergerán en la mayoría de los casos de temáticas ya bien conocidas, aun cuando el gusto por la innovación radical nos impulsa a renovar conceptos, a veces para mejor y otras veces, también, para peor. Por otro lado, la diversidad de origen de las contribuciones escritas en alguno de los tres idiomas de trabajo del ICOM, testimonian las diferencias importantes que existen en el seno del mundo de la museología, tanto en lo que concierne a su estado de desarrollo como en relación al patrimonio o a los públicos, pero también por lo que concierne a los fundamentos mismos de la museología. Sin dudas es el estudio de esta diversidad lo que constituye la esencia del trabajo del ICOFOM: reunir, ubicar geográficamente y sintetizar el conjunto de propuestas ligadas al campo museal. En este sentido, la publicación de estos artículos no hace más que iniciar el estudio de las tendencias que se desprenden de la museología actual, trabajo continuo y forzadamente inconcluso, pero que participa plenamente de una cierta idea de la investigación científica y del trabajo del investigador. 